\title{
Bioethanol produced from regenerative wooden resource to operate an organic Rankine cycle- waste heat recovery system in case of a tractor propulsion Diesel engine: preliminary simulation results
}

\author{
Bogdan Radu, and Alexandru Racovitza* \\ University POLITEHNICA Bucharest Dept. of Thermodynamics, Engines, Thermal and Refrigerant \\ Systems, 313 Splaiul Independentei, sector 6, 060042, Bucharest, Romania
}

\begin{abstract}
Bioethanol has become by nowadays a common-used organic agent by thermal installations in direct modes, like dual or single alternative fuel for classic engines, or in indirect modes, as primary source in fuel cells, or operating thermal energy recovery systems, which is the subject of the present work. Among all the other well-known industrial obtaining methods, avoiding higher costs and improving process efficiency, the enzymatic fermentation of the saccharide components coming from wooden biomass ensures a more profitable way to produce bioethanol, with the requested properties in order to operate as a thermal agent in an Organic Rankine Cycle (ORC) installation. The aim of using this system is to increase the efficiency of a tractor-turbocharged Diesel engine by its waste heat recovery (WHR).
\end{abstract}

\section{Introduction}

Since more decades, bioethanol has become a highly used alternative fuel in thermal engines operation, as single fuel or in combination with classic petroleum-based-on fuels [1]. There are also other indirect methods of its usage to contribute to the improvement of thermal systems operation. Newer Direct Ethanol Fuel Cells (DEFC) could easily use bioethanol as primary agent [2], supplying with electrical energy the batteries of the electrical engine of a hybrid or that of a $100 \%$ electric propulsion vehicle. Another effective method highlights itself to apply when using indirectly bioethanol to increase the performance and the efficiency of an internal combustion engine system consists in using an Organic Rankine Cycle (ORC) installation [3] in order to save an amount of the waste heat associated to the exhaust gas of the thermal engine. Figure 1 schematically describes the operation of this system.

\footnotetext{
*Corresponding author e-mail: alexandru_racovitza@yahoo.com
} 


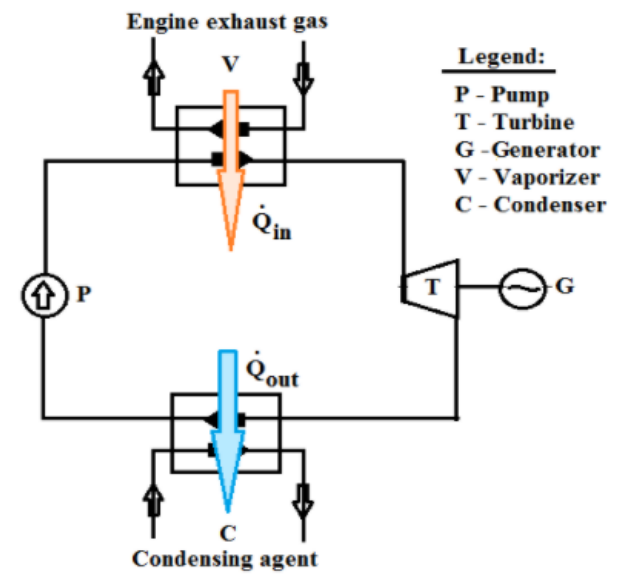

Fig. 1. The schematization of the ORC system operation [4].

One of the main issues consists in revealing the possibility to predict the optimal efficiency of an ORC system by applying its CAMD (Computer Aided Molecular Design), in order to establish a relationship between an optimum of the heat-cold sources temperature difference and the molecular structure of the ORC involved agents, as one of the studies highlighted by proposing a system operated by a range of 10 different alkanes [5].

Another multi-parameter optimization in case of high and medium value of the heat source temperature in terms of ORC cycle exergy maximization tends to offer a priority list of the followed agents characteristics: temperature, pressure, latent heat and specific heat [6]. The aim of increasing the degree of the energy recovery starts directly from the basic design of the engine installations, as other results are offered by a research which has identified a certain number of optimal design points [7].

Other research projects were focused on a detailed MBM (Moving Boundary Model), trying to highlight the response of the analyzed ORC system when transitory operated as functions of mass and energy flows through the configuration elements (pipes, pumps, valves, exchangers and expander) when calculating the system efficiency [8].

Furthermore, another model calibration based on the operation of a 6-cylinder turbocharged engine (Holset HDX55V) used a break specific fuel combustion (BSFC) map to estimate exhaust mass flow and temperature of the gas under different testing conditions to offer the necessary input of the ORC thermo-exergetic analysis. A useful decrease by 2$5 \%$ of the BSFC was noticed for the whole speed and load engine operating chart [9]. A top important issue remains the ecological properties of the ORC tested agents. Simulation and experimental research have already been giving motivating response in using advanced classes of freons $[4,10]$.

Bioethanol represents also an adequate agent due to its less toxicity and for its physical and chemical properties, as listed in Table 1. This type of alcohol fuel is obtained from totally regenerative vegetal resources, such as crops and wooden remaining. Fast cycle growing poplars are an appropriate resource to offer the biomass, from which extracted sugar compounds lead through fermentation to the requested bio-ethanol. Ethanol production from biomass uses two best applied procedures: hydrolysis and fermentation.

The biomass extraction from the vegetal resource contains a miscellaneous complex of polymers, namely the cellulose, the hemicellulose and the lignin. These ones are to react with acids, bases or with enzymes, this last process being the most revolutionary one, the followed results consisting in obtaining the sucrose, which further leads to bioethanol production [11]. 
Table 1. Bioethanol properties [1].

\begin{tabular}{|c|c|}
\hline Property / Unit & Value \\
\hline Equiv. molar weight (kg/kmole) & 46.1 \\
\hline $\mathrm{C}(\% \mathrm{w})$ & 52,2 \\
\hline $\mathrm{H}(\% \mathrm{w})$ & 13.1 \\
\hline $\mathrm{O}(\% \mathrm{w})$ & 34.8 \\
\hline $\mathrm{H}_{2} \mathrm{O}(\% \mathrm{w})$ & $<6.2$ \\
\hline Phosphorus (ppm) & - \\
\hline Sulfur (ppm) & - \\
\hline Density $\left(15^{\circ} \mathrm{C} / 1 \mathrm{bar}\right)\left(\mathrm{g} / \mathrm{cm}^{3}\right)$ & $0.8-0.82$ \\
\hline Boiling point $\left({ }^{\circ} \mathrm{C} / 1\right.$ bar $)$ & 78 \\
\hline Melting point $\left({ }^{\circ} \mathrm{C} / 1\right.$ bar $)$ & -114 \\
\hline Auto-ignition temperature $\left({ }^{\circ} \mathrm{C}\right)$ & 423 \\
\hline Low Heating Value (MJ/kg) & $25-27$ \\
\hline ON (Octane Number) & 108.6 \\
\hline Vaporization specific heat $(\mathrm{kJ} / \mathrm{kg})$ & 923 \\
\hline Specific heat $(\mathrm{kJ} / \mathrm{kg} \mathrm{K})$ & 2.4 \\
\hline
\end{tabular}

There are three well-known to transform the biomass into sugar elements: hydrolysis with diluted acids (Arkhanol) and hydrolysis using the enzymatic fermentation. As mentioned, the last method is a new and revolutionary process, prioritized during the last decades. The subsequent reactions are numbered as following [1,11,12]:

$$
\begin{aligned}
& \mathrm{C}_{12} \mathrm{H}_{22} \mathrm{O}_{11} \text { (sucrose) }+\mathrm{H}_{2} \mathrm{O} \rightarrow \text { (Invertasys/catalyzer) } \\
& \mathrm{C}_{6} \mathrm{H}_{12} \mathrm{O}_{6} \text { (fructose) }+\mathrm{C}_{6} \mathrm{H}_{12} \mathrm{O}_{6} \text { (glucose) } \\
& \mathrm{C}_{6} \mathrm{H}_{12} \mathrm{O}_{6} \text { (fructose/glucose) } \rightarrow \text { (Zimasys/catalyzer) } \\
& 2 \mathrm{C}_{2} \mathrm{H}_{5} \mathrm{OH} \text { (ethanol) }+2 \mathrm{CO}_{2} \uparrow
\end{aligned}
$$

The ethanol thus obtained must also follow a dehydration process, to eliminate the significant gained water amount. The elimination of water consists in a process of fractioned distillation. The lower condensing point of ethanol $\left(78.5^{\circ} \mathrm{C}\right)$ comparing to water $\left(100^{\circ} \mathrm{C}\right)$, at normal atmospheric pressure allows the condensation of the alcohol separately from water [11]. 
The proposed work is assuming as a main objective the identify by numerical simulation the potential of using bioethanol as the operating agent of an ORC-WHR system in case of a heavy-duty turbocharged Diesel engine. Once that first simulation results for particularly engine operating regimes would offer suggestive perspective to extend the testing domain, the present work will enrich its conclusions and would be a starting point to direct experimental validation and further on-board system implementation. The results will also favorize a potential new design of the waste heat recovery installation by means of optimizing the processes of heat exchange.

\section{Engine description and modelling}

The tested tractor engine is an IVECO Cursor 10-400 turbocharged Diesel engine, with its main features listed in Table 2.

Table 2. IVECO Cursor 10-400 engine specifications [13]

\begin{tabular}{|c|c|}
\hline Feature / Unit & Type/Value \\
\hline Rated power [kW/HP] & $294 / 400$ \\
\hline Nominal speed [rpm] & 2100 \\
\hline No. of cylinders & 6 \\
\hline Compression ratio & $16.5: 1$ \\
\hline Bore [mm] & 125 \\
\hline Stroke [mm] & 140 \\
\hline Swept volume [1] & 10.38 \\
\hline Fueling & Direct Injection \\
\hline Admission & Turbocharged \\
\hline
\end{tabular}

The engine is modelled by using AMESIM numerical code [14], by inserting the main parts of the engine [13], among which the most important one is the cylinder assemble, as showed in Figure 2. All the in-cylinder involved processes are all specific to a Diesel engine. Thus, of maximum interest are those given by the distribution system, by the air-fuel mixture formation and by the heat exchange. Auto-ignition and combustion are connected to the hypothesis of the finite volumes and the numerical code is solving the model proposed by Khmela [15].

The turbocharging phase is linked to the characteristics of a compressor operating maps. Corresponding to $2100 \mathrm{rpm}$ the power rated by the engine is $294 \mathrm{~kW}$, related to $151 \mathrm{mg}$ fuel dose injection, equivalent to $56.5 \mathrm{~kg} / \mathrm{h}$ fuel consumption. These lead to $192 \mathrm{~g} / \mathrm{kWh}$ brake fuel specific consumption (BSFC) value. Figure 3 shows the in-cylinder pressure and the temperatures traces, related to these specific operating conditions: $0.25 \mathrm{MPa}$ turbocharged pressure, turbo-compound speed of $86400 \mathrm{rpm}, 384 \mathrm{~g} / \mathrm{s}$ exhaust mass flow, exhaust temperature of $905 \mathrm{~K}$ and 1.54 as relative air-fuel ratio. 


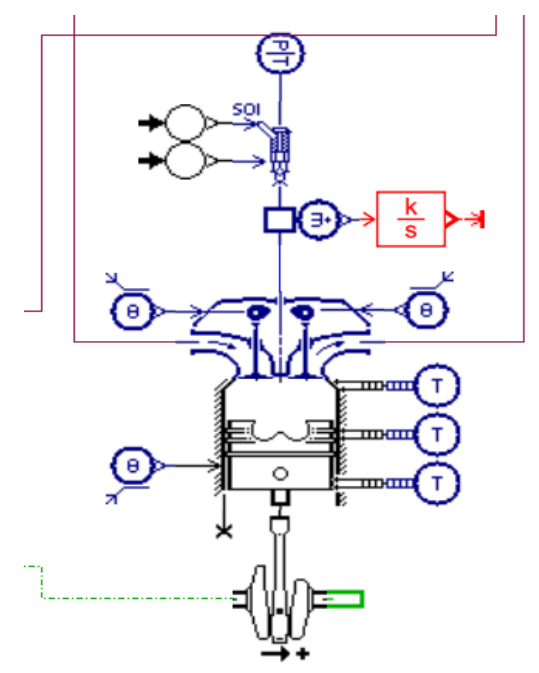

Fig. 2. Piston - Cylinder Model

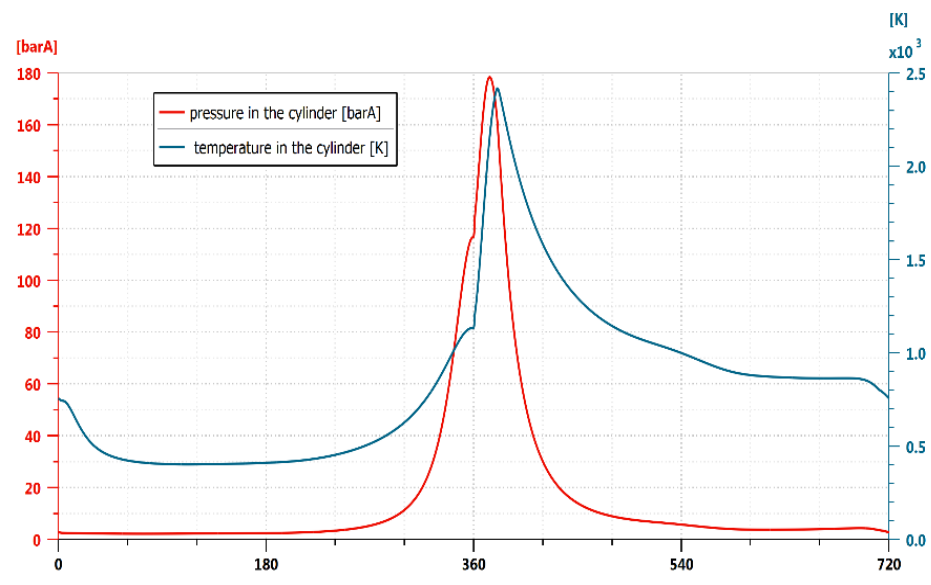

Fig. 3. In-cylinder pressure and temperature variation curves

\section{Modelling the ORC-WHR installation}

The operation of the installation is based on taking the heat value from exhaust gas of the engine and delivering it to the ORC system, operated by the bioethanol agent, so that it vaporizes through the vaporizer and consequently condenses, using a condenser and further transferring another amount of heat to the cold source, the cooling agent. The resulting energy difference between the two heat sources should be the cycle mechanical work, as the difference between what the expander (turbine) produces and what the pump consumes (see Figure 1).

The simulation of the exhaust gas flow heating effect is given by a boiler, completing the schematic, in order to operate with three parameters: the gas mass flow, the temperature and the composition of the gas, as assumed by the model.

The AMESIM numerical code helps in providing the schematization for three of the system basic elements [13]: the boiler (the vaporizer - Figure 4), the condenser (Figure 5) and the expander (the turbine-Figure 6). 


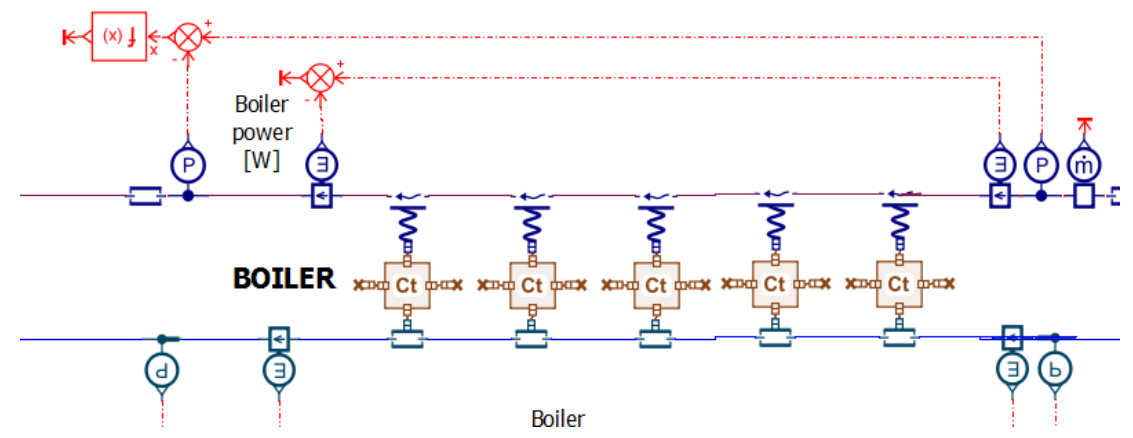

Fig. 4. The boiler model

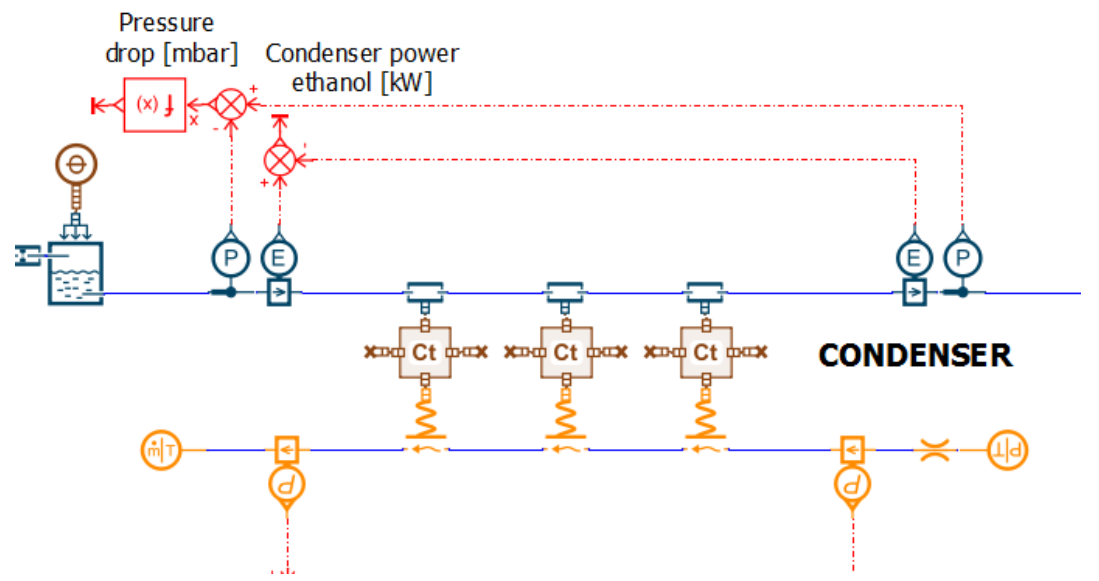

Fig. 5. The condenser model

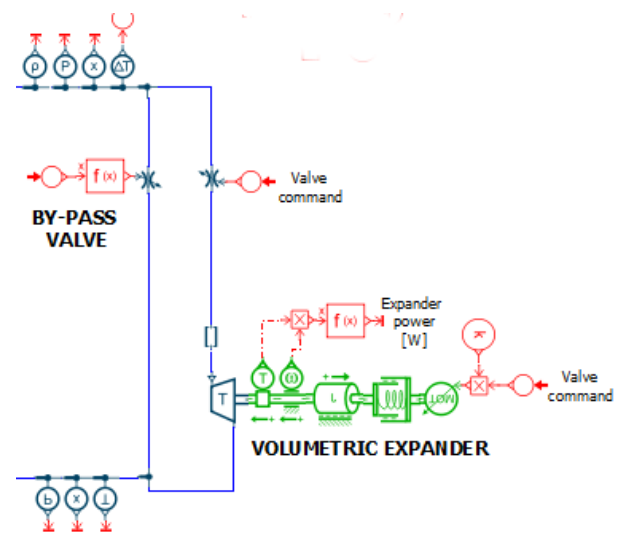

Fig. 6. The expander model 


\section{Simulation results}

The exploitation of the reach data proved to be a difficult process during the heat transfer from the gas to the Rankine fluid, because of the very unsteady character of the modelling, density and heat transfer coefficient having a rapid variation along the phase status exchange. Therefore, an extra number of recirculating points (5-pipes) inside the boiler needed to be adopted in order to obtain a stabilized data correlation.

After a significant number of iterations this stabilization reach for the Rankine agent a pressure of about 14 bar and a temperature of about $268^{\circ} \mathrm{C}$, corresponding to the thermodynamic zone of the overheated vapours of ethanol (at the outlet of pipe no.5 - see Figure 7). The fruitful power gained by the recovering system is calculated based on the temperature reached by the exhaust gas temperature, as highlighted in Figure 8.

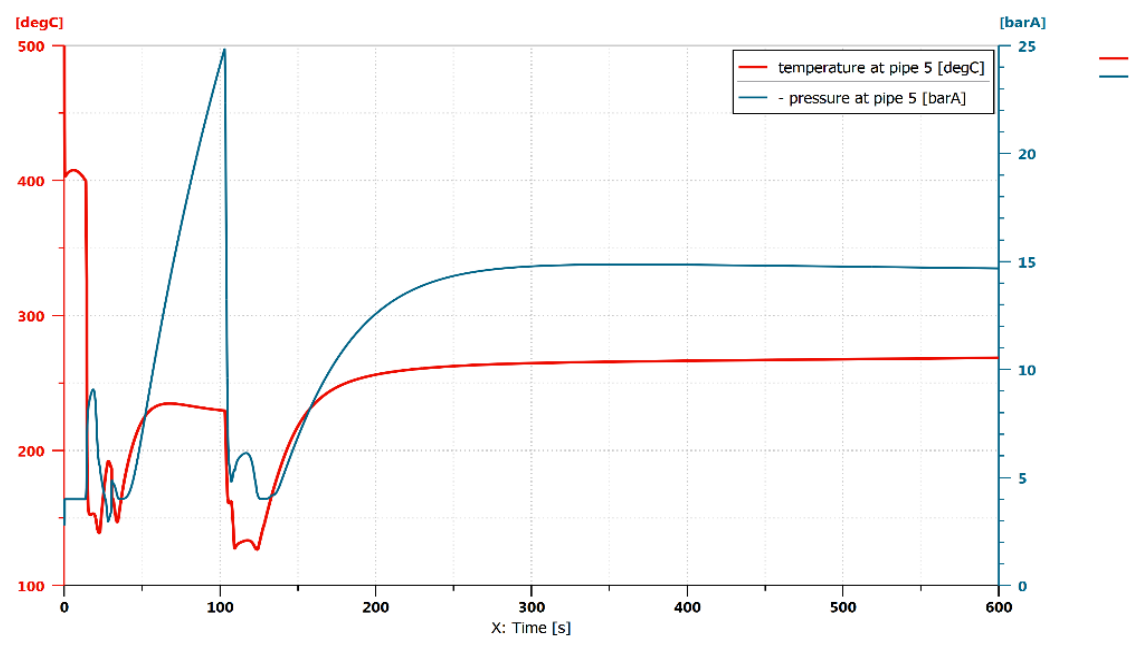

Fig. 7. Parameters' values stabilization for the Rankine agent in the boiler outlet

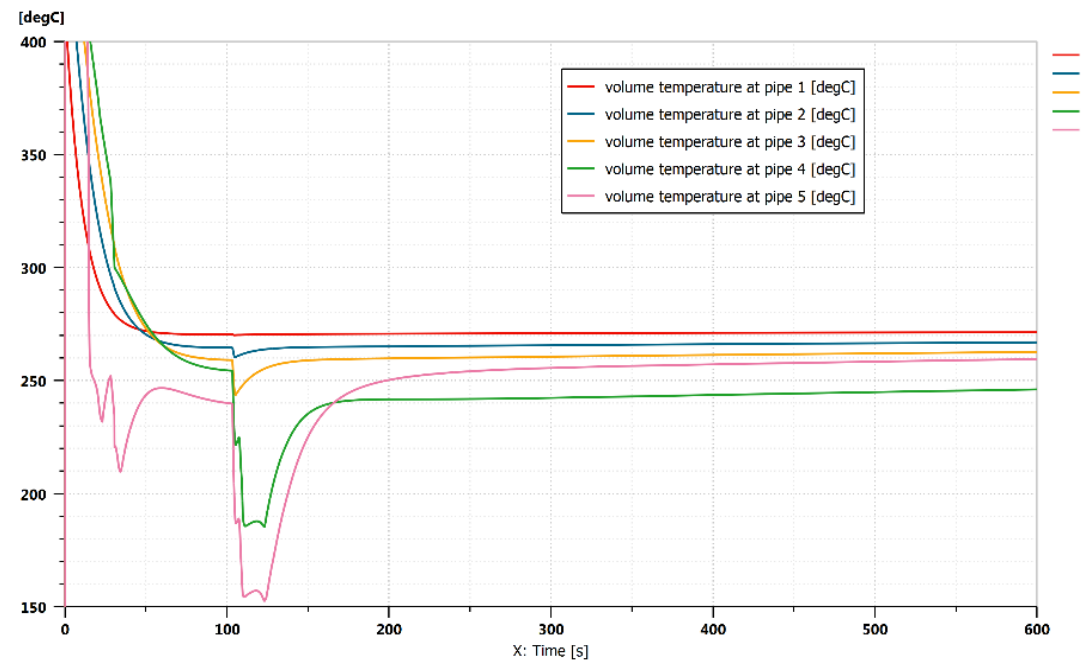

Fig. 8. Exhaust gas temperature variation 
The recovered reasonable level of the power is about $5 \mathrm{~kW}$, representing nominal engine operating conditions. At lower speeds and loads, other recovery methods are supposed to prove more efficient (using turbo-compound or thermo-electric effect configurations) [16].

\section{Further research}

In order to improve the efficiency of WHR-ORC installation, even at medium engine operating conditions, the heat quantity offered to the Rankine system could be increase by inserting in the agent circuit a pre-heating exchanger, having its heating source materialized by the engine cooling liquid, by means of radiator elimination and using a liquid-to-liquid type heat exchanger instead (as showed in Figure 9). A step even forward could be the use of the heat stored by the engine lubricating agent, used also in terms of preheating the Rankine organic agent. As a consequence, the whole installation efficiency could probably increase by certain percentage units, as already experimented, together with ensuring low emissions' levels and classic fuel economy [17].

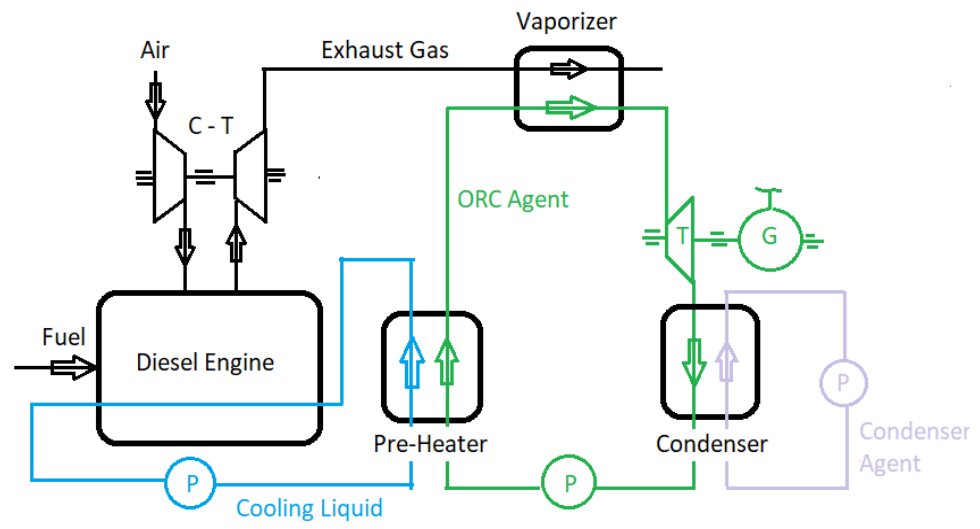

Fig. 9. WHR-ORC system improved configuration

\section{Conclusions}

A simulation work followed the main assumed goal of describing the operation of an ORC system, applied as a WHR method in case of a tractor Diesel engine, when applying bioethanol obtained by enzymatic fermentation process of the based-on-sugar products obtained from vegetal (poplar clones) biomass.

The gain by applying this method consists in a saving of approximately $5 \mathrm{~kW}(1.7 \%)$ from the total rated power $(294 \mathrm{~kW})$ of the engine, running at $2100 \mathrm{rpm}$ and at full load.

The simulation results are satisfactory enough to extend the simulation program to other engine operating regimes and to start a first series of experimental tests. Further simulation results should be also disposable as a matter of installation structure modification by adding pre-heating elements to improve the analyzed configuration. 


\section{References}

1. C. Cincu, L. Fara, A. Racovitza, L. Lobont, Cell. Chem. Technol., 45, 1-2 (2011)

2. A. Racovitza, Termotehnica J., XII, 1 (2008)

3. A. Royale, M. Simic, Procedia Comput. Sci. 60 (2015)

4. A. Racovitza, H. Pop, V. Apostol, T. Prisecaru, D. Taban, Rev. Chim, 71,1 (2020)

5. M. Fanxiao, W. Enhua, Z. Bo, Energy, 119, 119974 (2021)

6. T. Zhang, L. Liu, J. Hao, T. Zhu, G. Cui, Appl. Therm. Eng., 188, 116626 (2021)

7. X. Shi, X. Wang, J. Cai, Y. Gao, H. Tian, G. Shu, Energy Sci. Eng., 9, 2 (2011)

8. M.C. Esposito, N.Pompini, A.Gambarotta, V.Chandrasekaran, J.Zhou, M.Canova, IFAC-PapersOnLine 48-15 (2015)

9. A.M. Andwari, A. Pesiridis, V. Esfahanian, A.S. Zadeh, A. Karvountsis-Kontakiotis, V. Muralidharan, Energies, 10, 1087 (2017)

10. V. Darawuna, R.Songprakorpa, V.Monyakula, S.Thepaa, Energy Procedia, 79 (2015)

11. Gh. Hubca, A. Lupu, A.C. Cociasu, Bio-fuels:biodiesel, bioethanol, sun diesel (MatrixRom Press, Bucharest, 2008)

12. L. Fara, I. Istrate, I. Bitir, A. Racovitza et al., Research on energetically evaluation of rapid growing poplar clones in short production cycles (Research grant Kernel Program II, no.22092/2008)

13. B. Radu, A. Racovitza, E3S Web of Conferences, 112, 01001 (2019)

14. ***AMESIM IFP Engine Library Rev.14

15. F. Chmela, C. Orthaber, SAE paper 1999-01-0186 (1999)

16. B. Radu, A. Racovitza, MATEC Web of Conferences, 290, 06008 (2019)

17. J. Thaddaeus, G. Unachukwu, C. Mgbemene, A. Mohammed, A. Pesyridis, Int. J. Green Energy, 15, 100849 (2020) 